\title{
Histochemically Reactive Zinc in Plaques of the Swedish Mutant $\beta$-Amyloid Precursor Protein Transgenic Mice
}

\author{
Joo-Yong Lee, Inhee Mook-Jung, and Jae-Young Koh \\ National Creative Research Initiative Center for the Study of CNS Zinc and Department of Neurology, University of Ulsan \\ College of Medicine, Seoul 138-736, Korea
}

\begin{abstract}
Endogenous metals such as zinc may contribute to $\beta$-amyloid $(\mathrm{A} \beta)$ aggregation and hence the plaque formation. In the present study, we examined brains of four Swedish mutant amyloid precursor protein (APP) transgenic mice at 12 months of age for histochemically reactive zinc in the plaques. Here, we report that all the Congo red $(+)$ mature plaques contained chelatable zinc, as demonstrated by staining with the zinc-specific fluorescent dye 6-methoxy-8-quinolyl-para-toluenesulfonamide (TSQ). On the other hand, Congo red (-) preamyloid $A \beta$ deposits were not stained with TSQ. Interestingly, although cerebellum contained similar degree of preamyloid $A \beta$ deposits as cerebral cortex, it was completely devoid of Congo red- or TSQ-stained mature plaques. Although zinc from plaques was only slowly and partially removed by a specific
\end{abstract}

One of the hallmark pathological features of Alzheimer's disease (AD) is the accumulation of amyloid plaques in the brain. The main component of the amyloid plaque is the peptide fragment of $39-43$ amino acid residues $(\mathrm{A} \beta)$, derived from $\beta$-amyloid precursor protein (APP) of 695-771 amino acids (Kang et al., 1987). Recent studies suggest that abnormal processing of APP and accumulation of amyloid plaques may play a causal role in the pathogenesis of AD. First, all the identified mutant genes causing familial AD (APP and presenilin-1 and -2) have been shown to increase $\mathrm{A} \beta$ production (Price and Sisodia, 1998). Second, transgenic mice overexpressing human mutant APP develop not only the accumulation of amyloid plaques but also deficits in learning (Games et al., 1995; Hsiao et al., 1996). Finally, aggregated A $\beta$ induces neuronal death in cultures (Pike et al., 1993).

In light of evidence that $\mathrm{A} \beta$ accumulation and plaque formation play a pivotal role in the AD pathogenesis, understanding the precise mechanisms of the process may be crucial for contemplating effective treatments against AD. Recently, Bush et al. (1994a) and Atwood et al. (1998) showed that zinc and copper promote $\mathrm{A} \beta$ aggregation in test tube conditions and suggested that these endogenous metals may contribute to the process of the plaque formation. Corroborating this hypothesis, they showed that metal chelators increase extraction of $\mathrm{A} \beta$ from the human $\mathrm{AD}$ brains (Cherny et al., 1998). Furthermore, examination of AD brains

\footnotetext{
Received Nov. 2, 1998; revised March 8, 1999; accepted March 18, 1999.

This study was supported by Creative Research Initiatives of the Korean Ministry of Science and Technology (J.-Y.K.). We thank Dr. Karen Hsiao for generously donating the APP transgenic mice.

Correspondence should be addressed to Jae-Young Koh, National Creative Research Center for the Study of CNS Zinc, Department of Neurology, University of Ulsan College of Medicine, 388-1 Poongnap-Dong Songpa-Gu, Seoul 138-736, Korea.

Copyright (C) 1999 Society for Neuroscience $\quad 0270-6474 / 99 / 190001-05 \$ 05.00 / 0$
}

zinc remover, dithizone, treatment of brain sections with heparinase-III, which degrades heparan sulfate proteoglycan (HSPG), another major constituent of plaques, greatly fastened the zinc removal with dithizone.

The present study has demonstrated the presence of histochemically reactive zinc in plaques, but not preamyloid $A \beta$ deposits, of the Swedish mutant APP transgenic mice. Because preamyloid $A \beta$ deposits fail to develop into congophilic plaques in cerebellum where synaptic vesicle zinc is deficient, the synaptic zinc may be a necessary element in the plaque formation. In holding zinc inside plaques, HSPG may contribute in addition to $A \beta$.

Key words: $\beta$-amyloid; Alzheimer's disease; heparan sulfate proteoglycan; metal; cortex; cerebellum revealed that chelatable zinc is present in plaques and tangles (Suh et al., 1998). Although these data support the metal, in particular zinc, hypothesis in plaque formation, it is difficult to test this directly in human patients. Cell membrane-permeant metal chelators such as $N, N, N^{\prime}, N^{\prime}$-tetrakis(2-pyridylmethyl)ethylenediamine are highly toxic to neurons (Ahn et al., 1998). On the other hand, nontoxic extracellular metal chelators such as $\mathrm{Ca}$ EDTA do not cross the blood-brain barrier and hence should be applied into parenchyme or CSF. Because this requires invasive procedures, careful animal experiments are warranted before testing it in human patients. For this reason, we examined whether zinc is identifiable in plaques of transgenic mice overexpressing the Swedish mutant APP (Hsiao et al., 1996).

\section{MATERIALS AND METHODS}

Transgenic mice. Transgenic mice overexpressing Swedish mutant APP (Tg2576) (Hsiao et al., 1996) were generous gift from Dr. K. Hsiao (University of Minnesota, Minneapolis, MN). For the present study, four female $\mathrm{Tg} 2576$ mice at 12 months of age were used. According to the report of Hsiao et al. (1996), $\beta$-amyloid plaques begin to appear at 9 months after birth in the Tg2576 mouse brain.

This article is published in The Journal of Neuroscience, Rapid Communications Section, which publishes brief, peerreviewed papers online, not in print. Rapid Communications are posted online approximately one month earlier than they would appear if printed. They are listed in the Table of Contents of the next open issue of JNeurosci. Cite this article as: JNeurosci, 1999, 19:RC10 (1-5). The publication date is the date of posting online at www.jneurosci.org.

http://www.jneurosci.org/cgi/content/full/3087 


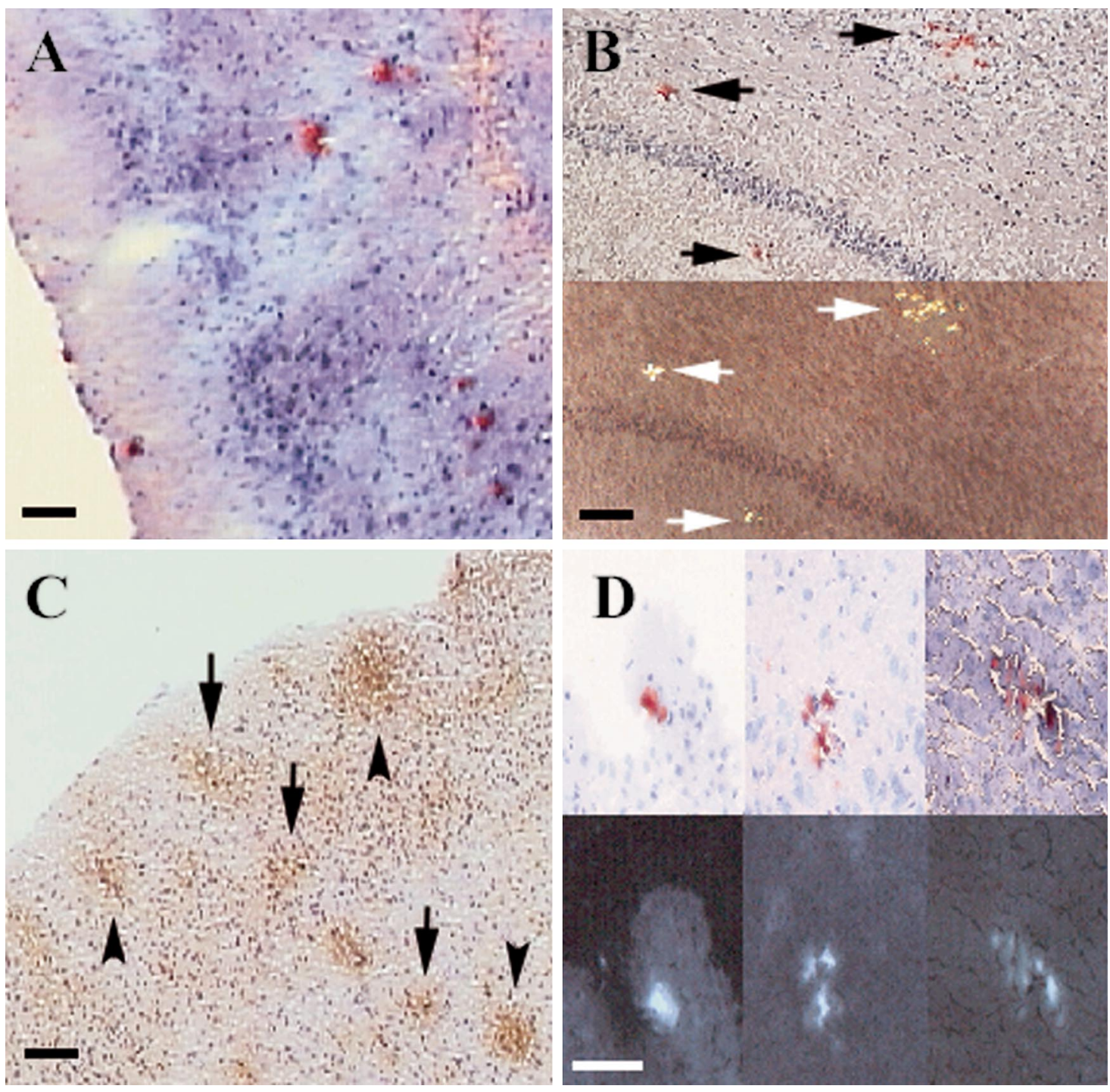

Figure 1. A, Cerebral cortex of an APP transgenic mouse at 12 months of age was stained with Congo red. Note numerous congophilic plaques. B, Hippocampus of another APP transgenic mouse with Congo red staining without (top) or with (bottom) polarization. Note that all Congo red ( + ) plaques exhibit apple green birefringence (arrows). $C$, Anti-A $\beta$ antibody (monoclonal antibody 4G8)-stained plaques (arrowheads; subsequently identified with Congo red staining) and preamyloid $\mathrm{A} \beta$ deposits (arrows) in cortex. $D$, Cortices were stained with Congo red (top) and subsequently with a specific zinc fluorescent dye, TSQ (bottom). Note that all congophilic plaques were subsequently stained with TSQ. Changing the order of staining, first TSQ and then Congo red, produced identical results. Scale bars, $500 \mu \mathrm{m}$.

Tissue preparation and Congo red staining. Brains of Tg2576 mice were harvested and immediately frozen in dry ice. Coronal brain sections of 10 $\mu \mathrm{m}$ thickness were obtained using a cryostat (Leica, Nussloch, Germany) and mounted on glass slides. Plaques were identified by staining brain sections with Congo red. After staining in Mayer's hematoxylin solution for $10 \mathrm{~min}$, brain sections were rinsed in tap water for $5 \mathrm{~min}$ and incubated in alkaline sodium chloride solution for $20 \mathrm{~min}$. Brain sections were then stained with alkaline Congo red solution $(0.2 \%$ in $80 \%$ ethanol saturated with sodium chloride; Sigma, St. Louis, MO) and washed in absolute ethanol. Congo red-stained sections were observed under light microscope (conventional and polarized).

Immunocytochemistry. $\mathrm{A} \beta$ deposits inside and outside congophilic plaques were visualized immunocytochemically with mouse monoclonal antibody 4G8 (Senetek, St. Louis, MO) specific for A $317-24$. Immunocytochemistry was performed using the avidin-biotin-horseradish peroxidase method (Vector Laboratories, Burlingame, CA). Briefly, frozen brain sections were blocked with horse serum and immunoreacted overnight with $4 \mathrm{G} 8$ at 1:1000 dilution. After reaction with biotinylated secondary antibody (horse anti-mouse $\operatorname{IgG}$ ), sections were treated with avidin-horseradish peroxidase solution. After thorough rinsing with PBS, sections were incubated in solution containing $0.015 \%$ diaminobenzidine and $0.001 \%$ hydrogen peroxide.
To immunocytochemically verify the degradation of heparan sulfate proteoglycan (HSPG) in plaques after treatment with heparinase-III, anti- $\Delta$-heparan sulfate antibody $3 \mathrm{G} 10$ (Seikagaku, Tokyo, Japan) specific for heparinase-digested heparan sulfate side chains was used (1:50).

Fluorescent zinc staining. To examine the presence of chelatable zinc in plaques, brain sections were stained with 6-methoxy-8-quinolyl-paratoluenesulfonamide (TSQ) (Frederickson et al., 1987). Without fixation, frozen sections were immersed for $90 \mathrm{sec}$ in TSQ solution $(4.5 \mu \mathrm{M}$; Molecular Probes, Eugene, OR) in $140 \mathrm{~mm}$ sodium barbital and $140 \mathrm{~mm}$ sodium acetate buffer, $\mathrm{pH}$ 10. After washing with normal saline, TSQ fluorescence was examined under a fluorescence microscope with an ultraviolet filter (excitation, 355-375 nm; dichroic, $380 \mathrm{~nm}$; barrier, $420 \mathrm{~nm})$.

Removal of tissue zinc with dithizone. Dithizone specifically removes zinc from tissue (Koh et al., 1996). Brain sections were immersed in 10 $\mathrm{mm}$ dithizone for $5 \mathrm{~min}$ at room temperature. After rinsing with normal saline, brain sections were examined for TSQ fluorescence.

Heparinase-III treatment. To digest HSPG in brain sections, frozen brain sections were incubated at $37^{\circ} \mathrm{C}$ for $2 \mathrm{hr}$ in heparinase-IIIcontaining PBS ( $2 \mathrm{U}$ in $200 \mu \mathrm{l}$; Sigma). The enzyme reaction was terminated by rinsing brain sections multiple times with normal saline. 


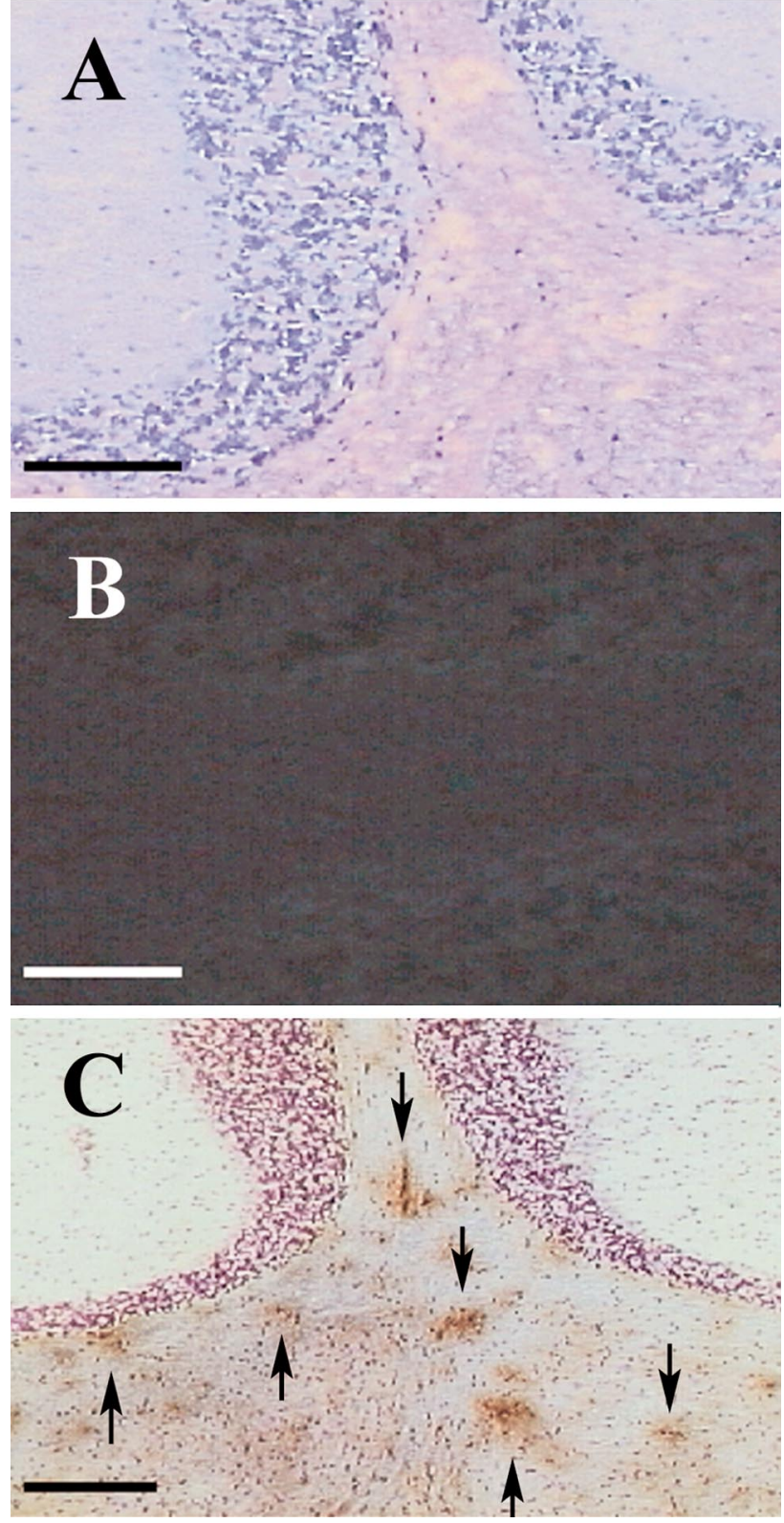

Figure 2. A, Congo red staining of cerebellum revealed no congophilic plaque. $B$, No TSQ-stainable structure, plaque or presynaptic zinc, was found in cerebellum. $C$, Anti-A $\beta$ antibody revealed similar amounts of preamyloid $\mathrm{A} \beta$ deposits (arrows) in cerebellum as in cerebral cortex (Fig. $1 C)$. Scale bars, $500 \mu \mathrm{m}$.

\section{RESULTS}

Brains of four Swedish mutant APP transgenic mice were examined at 12 months of age, when they developed numerous congophilic plaques with apple green birefringence in cerebral cortex and hippocampus, as previously reported (Hsiao et al., 1996) (Fig. $1 A, B)$. On the other hand, immunocytochemical staining of an adjacent section with anti-A $\beta 17-24$ antibody recognized not only congophilic plaques but also more widespread preamyloid $\mathrm{A} \beta$ deposits (Fig. 1C). TSQ staining revealed that all the congophilic plaques contained chelatable zinc (Fig. 1D). However, preamyloid $\mathrm{A} \beta$ deposits were not stained for zinc with TSQ. Changing the order of staining, first TSQ and then Congo red, did not alter the correlation, ruling out the possibility that zinc fluorescence is merely an artifact of Congo red staining.
In contrast to forebrain, cerebellum lacks synaptic zinc (Frederickson, 1989; Fig. 2B). Consistent with the hypothesis that synaptic zinc may contribute to plaque formation, cerebellum contained neither Congo red-stained (Fig. $2 A$ ) nor TSQ-stained (Fig. $2 B$ ) plaques. However, cerebellum still exhibited a substantial amount of preamyloid $\mathrm{A} \beta$ deposits (Fig. $2 C$ ), as did cortex and hippocampus.

Interestingly, treatment of plaques with a specific zinc remover, dithizone (10 mM) (Koh et al., 1996), for 5 min, which abolished background zinc fluorescence presumably in presynaptic vesicles, did not much reduce the fluorescence in plaques (Fig. 3B). This suggested that some of the zinc in plaques was not easily accessible for dithizone. Because HSPG, another major constituent of plaques, may contribute to $\mathrm{A} \beta$ aggregation (Snow et al., 1988; Brunden et al., 1993), we examined whether it is involved in holding zinc. The treatment of adjacent brain sections of the above with heparinase-III for $2 \mathrm{hr}$ degraded HSPG in plaques, as evidenced by the emergence of immunoreactivity to an antibody (3G10) specific for digested heparan sulfate side chains (Fig. 3E). The heparinase-III treatment rendered zinc removal by dithizone much faster. Subsequent to the heparinase-III treatment, $5 \mathrm{~min}$ exposure to dithizone completely abolished TSQ fluorescence in the plaques (Fig. $3 C$, compare with $B$ ). In contrast, even $30 \mathrm{~min}$ exposure to $10 \mathrm{~mm}$ dithizone in naïve tissue only partially removed zinc in plaques (Fig. 3D). This finding suggests that HSPG indeed contributes to holding zinc in plaques. However, despite complete removal of zinc, plaques were still stained with anti-A $\beta$ antibody (Fig. $3 F$ ) or Congo red (Fig. $3 G$ ).

\section{DISCUSSION}

Our findings have demonstrated that TSQ-stainable zinc is invariably present in mature congophilic amyloid plaques but not in preamyloid $\mathrm{A} \beta$ deposits of the Swedish mutant APP transgenic mice. Combined with a report showing that human AD brains also contain chelatable zinc in plaques (Suh et al., 1998), the present results suggest that the presence of chelatable zinc may be a universal feature of mature congophilic plaques. Because TSQ and dithizone are specific for zinc, the fluorescent signal in plaques has likely originated from zinc. With the histochemical methods used in the present study, however, we cannot rule out a possible additional contribution of copper in the plaque formation (Atwood et al., 1998). In addition, because TSQ is a dye with relatively low affinity for zinc (Frederickson et al., 1987), it remains a possibility that low-level or tightly bound zinc is present even in preamyloid $\mathrm{A} \beta$ deposits. In any case, the fact that a large amount of chelatable zinc is invariably present in mature congophilic plaques supports the hypothesis that endogenous zinc contributes to the maturation of $\mathrm{A} \beta$ plaques (Bush et al., 1994a). It has been shown that zinc binds to $\mathrm{A} \beta$ with high and low affinities, indicating the presence of specific binding sites (Bush et al., 1994b).

Interestingly, cerebellum lacking synaptic vesicle zinc (Frederickson, 1989), but containing similar amounts of tissue copper (Sato et al., 1994), does not develop plaques in transgenic mice (present study) as well as in human AD brains (Joachim et al., 1989), even if cerebellum has substantial preamyloid $\mathrm{A} \beta$ deposits. Although these findings argue that zinc accumulation is unlikely only a result of its nonspecific binding to a preformed $\beta$-pleated sheet, the present study cannot completely rule out this possibility. However, zinc preferentially binds to soluble A $\beta$ ( $\alpha$-helical form) (Huang et al., 1997). Furthermore, metal binding may promote conformational changes of $\mathrm{A} \beta$ to $\beta$-pleated sheet (Vyas 



Figure 3. $A-D$, Cerebral cortex stained with TSQ before $(A)$ and after 5 min treatment with 10 mm dithizone $(B)$. Five minutes of dithizone treatment abolished background zinc staining but only a fraction of zinc staining in plaques. After $2 \mathrm{hr}$ of treatment of an adjacent section with heparinase-III, however, the same dithizone treatment $(5 \mathrm{~min}, 10 \mathrm{~mm})$ completely removed all the zinc $(C)$. In contrast, even 30 min of treatment with 10 mM dithizone did not completely remove the TSQ fluorescence in the plaque $(D)$. E, After treatment for $2 \mathrm{hr}$ with heparinase-III, the antibody specific for digested heparan sulfate side chains (3G10) stained plaques, indicating that HSPG was degraded with the enzyme treatment. TSQ staining was not altered by heparinase treatment alone. $F$, A brain section was stained with anti-A $\beta$ antibody after complete removal of zinc (heparinase-III and dithizone treatments). Although zinc was completely removed $(C)$, the immunoreactivity of plaques to $4 \mathrm{G} 8$ did not change. $G$, Plaques retained stainability to Congo red after the complete removal of zinc. Scale bars, $500 \mu \mathrm{m}$.

and Duffy, 1995). These data favor the idea that the zinc binding may be a trigger for the conformation change of $\mathrm{A} \beta$.

Further supporting the involvement of synaptic zinc rather than the ambient submicromolar zinc or copper in extracellular fluid (Bush et al., 1994a) in the maturation of $\mathrm{A} \beta$ plaques is the evidence that $100 \mu \mathrm{M}$ concentrations of zinc are needed to promote A $\beta$ aggregation (Esler et al., 1996). At the peak of neuronal activity, such high concentrations of zinc can be attained by the release of synaptic zinc (Assaf and Chung, 1984).

In addition to $\mathrm{A} \beta$, our findings suggest that HSPG may be also involved in the zinc binding. Heparin and HSPG contain metalbinding domains (Whitfield and Sarkar, 1992). A recent study showed that the presence of zinc could increase in the APP affinity for heparin (Multhaup et al., 1995). Hence, zinc may play a role in linking $\mathrm{A} \beta$ and $\mathrm{HSPG}$ to form dense congophilic plaques in AD.

The APP transgenic mice seem to be an ideal model to directly test the hypothesis that endogenous synaptic zinc is necessary for the plaque formation. For example, determining effects of metal chelators administered into the brain or CSF during the time window of the plaque formation in these mice ( $\geq 9$ months of age) may be revealing. Additionally, application of zinc into cerebellum of the Swedish APP transgenic mice, where preamyloid A $\beta$ deposits are abundant but plaques are lacking, may provide a parallel clue to this theory.

\section{REFERENCES}

Ahn YH, Kim YH, Hong SH, Koh JY (1998) Depletion of intracellular zinc induces protein synthesis-dependent neuronal apoptosis in mouse cortical culture. Exp Neurol 154:47-56.

Assaf SY, Chung SH (1984) Release of endogenous $\mathrm{Zn}^{2+}$ from brain tissue during activity. Nature 308:734-736.

Atwood CS, Moir RD, Huang X, Scarpa RC, Bacarra NM, Romano DM, Hartshorn MA, Tanzi RE, Bush AI (1998) Dramatic aggregation of Alzheimer $\mathrm{A} \beta$ by $\mathrm{Cu}(\mathrm{II})$ is induced by conditions representing physiological acidosis. J Biol Chem 273:12817-12826.

Brunden KR, Richter-Cook NJ, Chaturvedi N, Frederickson RC (1993) $\mathrm{pH}$-dependent binding of synthetic beta-amyloid peptides to glycosaminoglycans. J Neurochem 61:2147-2154.

Bush AI, Pettingell WH, Multhaup G, de Paradis M, Vonsattel JP, Gusella JF, Beyreuther K, Masters CL, Tanzi RE (1994a) Rapid induction of Alzheimer A beta amyloid formation by zinc. Science 265:1464-1467.

Bush AI, Pettingell WH, Paradis MD, Tanzi RE (1994b) Modulation of A beta adhesiveness and secretase site cleavage by zinc. J Biol Chem 269:12152-12158.

Cherny RA, Legg JT, Beyreuther K, Tanzi RE, Masters CL, Bush AI (1998) Differential effects of chelators upon the solubilization of cerebral A $\beta$ deposits in post-mortem Alzheimer and control brain tissue. The 6th International Conference on Alzheimer's Disease and Related 
Disorders, Amsterdam, The Netherlands. Neurobiol Aging 19[Suppl 4S]:470.

Esler WP, Stimson ER, Jennings JM, Ghilardi JR, Mantyh PW, Maggio JE (1996) Zinc-induced aggregation of human and rat beta-amyloid peptides in vitro. J Neurochem 66:723-732.

Frederickson CJ (1989) Neurobiology of zinc and zinc-containing neurons. Int Rev Neurobiol 31:145-238.

Frederickson CJ, Kasarskis EJ, Ringo D, Frederickson RE (1987) A quinoline fluorescence method for visualizing and assaying the histochemically reactive zinc (bouton zinc) in the brain. J Neurosci Methods 20:91-103.

Games D, Adams D, Alessandrini R, Barbour R, Berthelette P, Blackwell C, Carr T, Clemens J, Donaldson T, Gillespie F, Guid T, Hagopian S, Johnson-Wood K, Lee M, Leibowitz P, Lieberburg I, Montoya-Zavala M, Mucke L, Power M, Schenk D, Seubert P, Snyder B, Soriano F, Tan H, Vitale J, Wadsworth S, Wolozin B, Zhao J (1995) Alzheimer-type neuropathology in transgenic mice overexpressing V717F beta-amyloid precursor protein. Nature 373:523-527.

Hsiao K, Chapman P, Nilsen S, Eckman C, Harigaya Y, Younkin S, Yang F, Cole G (1996) Correlative memory deficits, Abeta elevation, and amyloid plaques in transgenic mice. Science 274:99-102.

Huang X, Atwood CS, Moir RD, Hartshorn MA, Vonsattel JP, Tanzi RE, Bush AI (1997) Zinc-induced Alzheimer's Abeta1-42 aggregation is mediated by conformational factors. J Biol Chem 272:26464-26470.

Joachim CL, Morris JH, Selkoe DJ (1989) Diffuse senile plaques occur commonly in the cerebellum in Alzheimer's disease. Am J Pathol 135:309-319.

Kang J, Lemaire HG, Unterbeck A, Salbaum JM, Masters CL, Grzeschik KH, Multhaup G, Beyreuther K, Muller-Hill B (1987) The precursor of Alzheimer's disease amyloid A4 protein resembles a cell-surface receptor. Nature 325:733-736.

Koh JY, Suh SW, Gwag BJ, He YY, Hsu CY, Choi DW (1996) The role of zinc in selective neuronal death after transient global cerebral ischemia. Science 272:1013-1016.

Multhaup G, Mechler H, Masters CL (1995) Characterization of the high affinity heparin binding site of the Alzheimer's disease beta A4 amyloid precursor protein (APP) and its enhancement by zinc(II). J Mol Recognit 8:247-257.

Pike CJ, Burdick D, Walencewicz AJ, Glabe CG, Cotman CW (1993) Neurodegeneration induced by beta-amyloid peptides in vitro: the role of peptide assembly state. J Neurosci 13:1676-1687.

Price DL, Sisodia SS (1998) Mutant genes in familial Alzheimer's disease and transgenic models. Annu Rev Neurosci 21:479-505.

Sato M, Ohtomo K, Daimon T, Sugiyama T, Iijima K (1994) Localization of copper to afferent terminals in rat locus ceruleus, in contrast to mitochondrial copper in cerebellum. J Histochem Cytochem 42:1585-1591.

Snow AD, Mar H, Nochlin D, Kimata K, Kato M, Suzuki S, Hassell J, Wight TN (1988) The presence of heparan sulfate proteoglycans in the neuritic plaques and congophilic angiopathy in Alzheimer's disease. Am J Pathol 133:456-463.

Suh SW, Jensen KB, Jensen MS, Silva DS, Kesslak P, Danscher G, Frederickson CJ (1998) Histologic evidence of a zinc role in Alzheimer's disease. Soc Neurosci Abstr 24:1217.

Vyas SB, Duffy LK (1995) Stabilization of secondary structure of Alzheimer beta-protein by aluminum (III) ions and D-Asp substitutions. Biochem Biophys Res Commun 206:718-723.

Whitfield DM, Sarkar B (1992) Heavy metal binding to heparin disaccharides. II. First evidence for zinc chelation. Biopolymers 32:597-619. 